\title{
PHYTOCHEMICAL SCREENING AND ANTIMICROBIAL ACTIVITY OF THUJA OCCIDENTALIS SEEDS EXTRACTS AGAINST THE ISOLATED COMMON SKIN INFECTING MICROORGANISMS
}

\author{
IKRAM MOHAMED ELTAYEB ${ }^{*}$, ABDEEN SALIM HAMID ${ }^{1}$
}

\author{
1Department of Pharmacognosy, Faculty of Pharmacy, University of Medical Sciences and Technology, Khartoum, Sudan
}

Email: kramela_07@yahoo.com

Received: 13 Jul 2017 Revised and Accepted: 21 Sep 2017

\section{ABSTRACT}

Objective: This study represents the first attempt to investigate the antimicrobial activity of Thuja occidentalis seeds extracts against the isolated skin infecting microorganisms.

Methods: T. occidentalis seeds were powdered and extracted continuously by Soxhlet apparatus using $96 \%$ ethanol to obtain the total crude ethanolic extract. The extracts with increasing polarity were successively prepared with petroleum ether, chloroform, ethyl acetate, and methanol using the Soxhlet apparatus.

The extracts were screened for their phytochemical constituents. Their antimicrobial activity against standards microorganism and the isolated skin infecting microorganisms was evaluated using the agar diffusion method.

Results: The result revealed the presence of flavonoids, alkaloids, terpenoids, tannins and cardiac glycosides. The antimicrobial activity result showed that Escherichia coli, Pseudomonas aeroginosa, Staphylococcus aureus, Bacillus subtilis and Candida albicans were found to be sensitive to the extracts of $T$. occidentalis seeds with inhibition zones range between $20 \pm 0.57-12 \pm 1.25$ mm. The isolated skin infecting microorganisms; Staphylococcus aureus and Staphylococcus epidermidis were found to be highly susceptible to the extracts of T. occidentalis seeds with inhibition zones of $28 \pm 1.02-22 \pm 0.45 \mathrm{~mm}$ and minimum inhibitory concentration (MIC) values of $6.25 \mathrm{mg} / \mathrm{ml}$.

Conclusion: From the results it concludes, T. occidentalis seeds extracts had a considerable level of antimicrobial activity. They are more effective towards gram-positive than gram-negative bacteria. Hence, the active principles present in the extracts are particularly powerful effective against the skin infected isolated bacteria. In conclusion, there is a proportional increasing in the antimicrobial activity with increase of the solvents polarity. This may attribute to the fact that the chemical constituents responsible for the antimicrobial activity are of high polarity, such as tannins.

Keywords: Thuja occidentalis, Phytochemical Screening, Antimicrobial Activity, Isolated, Common Skin, Infecting, Microorganisms

(C) 2017 The Authors. Published by Innovare Academic Sciences Pvt Ltd. This is an open access article under the CC BY license (http://creativecommons.org/licenses/by/4.0/) DOI: http://dx.doi.org/10.22159/ijpps.2017v9i11.21310

\section{INTRODUCTION}

The plants are of great importance to the health of individuals and communities whereas, about $80 \%$ of world's populations rely on traditional medicine for their primary healthcare needs and the most of this therapy use plant extracts and their active compounds. The various type of secondary metabolites produced by medicinal plants such as alkaloids, flavonoids, steroids, phenolics, terpenes, volatile oils and other are well known for their medicinal use in traditional systems of medicine, folk medicines, modern medicines and pharmaceutical intermediates. Nowadays plant-derived substances have been of great interest owing to their versatile applications in the primary health care needs $[1,2]$.

Thuja occidentalis is one of the great importance in traditional medicine which it is widely used as a medicinal plant since 16th century [3]. T. occidentalis belongs to Cupressaceae family, and commonly known as Thuja is an evergreen coniferous tree use traditionally for treating of many diseases, mainly use as antimicrobial agent to treat skin infection; it has been used to treat conditions such as bronchial catarrh, enuresis, cystitis, psoriasis, uterine carcinomas, amenorrhea and rheumatism [4]. It is well known as antimicrobial, anticancer, analgesic and insecticide agent [5-8].

Skin infections such as abscesses, carbuncles and furuncles are known to becaused by several organisms whereas, Staphylococcus aureus is considered to be an almost-universal cause of several skin conditions. It is considered to be the most common organism implicated in both skin and soft tissue infections $[9,10]$. In addition to Staphylococcus epidermidis is commonly associated with skin infections [11].

According to the traditional use of T. occidentalis in the treatment of skin infections, in addition to taking into account the universal and common agents cause skin infection the present study was aimed, at the extraction of phytochemicals from T. occidentalis and evaluation of their antibacterial against Staphylococcus aureus and Staphylococcus epidermidis. Firstly the screened of its general antimicrobial activity against the common standard microorganisms (gram -ve bacteria, gram -ve bacteria and fungus) must be done.

\section{MATERIALS AND METHODS}

\section{Plant material collection and preparation}

Dried seeds of T. occidentalis were collected from the local market at Omdurman, Sudan in October 2015 as it was recommended by several traditional plant users for treating several dermatological conditions. This was then authenticated by taxonomist at the National Centre for Research/Sudan. The voucher specimens; IKR2, October-2015 were deposited at Pharmacognosy Department, Faculty of Pharmacy, University of Medical Science and Technology (UMST). The collected specimen was preserved for further studies.

\section{Preparation of $T$. occidentalis seeds extracts}

The collected plant samples were cleaned, grounded into fine powder and used for the preparation of five extracts of T. occidentalis. Hundred gm of plant powder was extracted with $96 \%$ ethanol using Soxhlet apparatus at $40{ }^{\circ} \mathrm{C}$ for $48 \mathrm{~h}$. to prepare the total crude ethanolic extract. Other $100 \mathrm{gm}$ of powder was extracted successively with solvents of increasing polarity; petroleum ether, chloroform, ethyl acetate and methanol. All extracts were evaporated to dryness by a rotary evaporator, their percentage yields were determined and then stored at $4{ }^{\circ} \mathrm{C}$ for further investigation.

\section{Phytochemical screening test}

The phytochemical constituents of the extracts were detected using standard procedures as described by Trease and Evans [12] and Sofowora, [13]. 


\section{Collection and preparation of the isolate bacteria}

The skin infected samples were collected from the Khartoum Dermatological Diseases Hospital/Sudan, and the bacteria were isolated and identified by a microbiologist at the National Centre for Research/Sudan. The isolated bacteria were cultured in agar media and incubated for $24 \mathrm{~h}$ at $37^{\circ} \mathrm{C}$, and then the antimicrobial test was conducted.

\section{Antimicrobial bioassay}

Antimicrobial testing was carried out using agar diffusion method with some minor modification [14]. Nutrient agar media was used as a growth medium for the bacterial organisms. Another growth medium composed of sabouraud dextrose powder was prepared for promoting fungal growth. The media was placed in an autoclave using the following conditions $37^{\circ} \mathrm{C}$ and $15 \mathrm{lbs}$ pressure for $15 \mathrm{~min}$ for sterilization. The media $(20 \mathrm{ml})$ was then poured in a petri dish under aseptic conditions and $(0.2 \mathrm{ml})$ of the intended microorganism was introduced into prepared media. After the media had solidified, two discs containing the prepared extracts of $T$. occidientalis were added in each plate. Hence, 5 different discs were prepared using the $96 \%$ ethanol total extract, petroleum ether, chloroform, ethyl acetate and methanol extracts. The experiment was performed in triplicate,

Determination of the minimum inhibitory concentrations (MIC)

The antimicrobial activity of T. occidentalis extracts with serial dilution of $100 \mathrm{mg} / \mathrm{ml}, 50 \mathrm{mg} / \mathrm{ml}, 25 \mathrm{mg} / \mathrm{ml}, 12.5 \mathrm{mg} / \mathrm{ml}$ and $6.25 \%$ $\mathrm{mg} / \mathrm{ml}$ were evaluated using agar diffusion method [14] to determine the minimum inhibitory concentration (MIC) of the extracts sufficient to prevent the growth of the skin infected microorganisms.

\section{RESULTS}

\section{Percentage Yields}

T. occidentalis seeds extracts produced by using of various solvents were found to be of quite variable percentages yields (table 1). Less polar solvents were possessing modest values, such as petroleum ether $(1.3 \%)$ and chloroform (4.1\%), whereas, the more polar solvents; ethyl acetate (64.9\%) and methanol (15.2\%) had more substantial values. The total ethanol (96\%) extract had a percentage yield of $73.7 \%$.

Table 1: Percentage yields of $T$. occidentalis seeds extracts

\begin{tabular}{lll}
\hline Plant extract & Extract yield (g/100g) & Percentage yield (w/w) \\
\hline Total (crude) ethanol & 73.7 & $73.7 \%$ \\
Petroleum Ether & 1.3 & $1.3 \%$ \\
Chloroform & 4.1 & $4.1 \%$ \\
Ethyl acetate & 64.9 & $64.9 \%$ \\
Methanol & 15.2 & $15.2 \%$ \\
\hline
\end{tabular}

\section{Phytochemical screening}

The phytochemical screening of $T$. occidentalis seeds extracts (table

2) revealed the presence of tannin in all assessed extracts.

Alkaloid was absent in petroleum ether and ethyl acetate extracts. Carbohydrates, steroids and saponins were not detected in any of the extracts.

Table 1: Qualitative phytochemical screening of $T$. occidentalis seeds extracts

\begin{tabular}{lllll}
\hline phytochemicals & Total ethanol extract & $\begin{array}{l}\text { Petroleum ether } \\
\text { extract }\end{array}$ & $\begin{array}{l}\text { Chloroform } \\
\text { extract }\end{array}$ & Ethyl acetate Ether \\
\hline Carbohydrates & - & - & - & - \\
Reducing Sugar & + & - & - & - \\
Compound Reducing sugar & + & + & - & + \\
Flavanoids & + & - & + & + \\
Tannins & ++ & + & + & + \\
Alkaloids & + & - & + & - \\
Sterols & - & - & - & + \\
Cardiac Glycosides & + & - & - & + \\
Terpenoids & + & - & - & + \\
Saponins & - & - & - & + \\
\hline
\end{tabular}

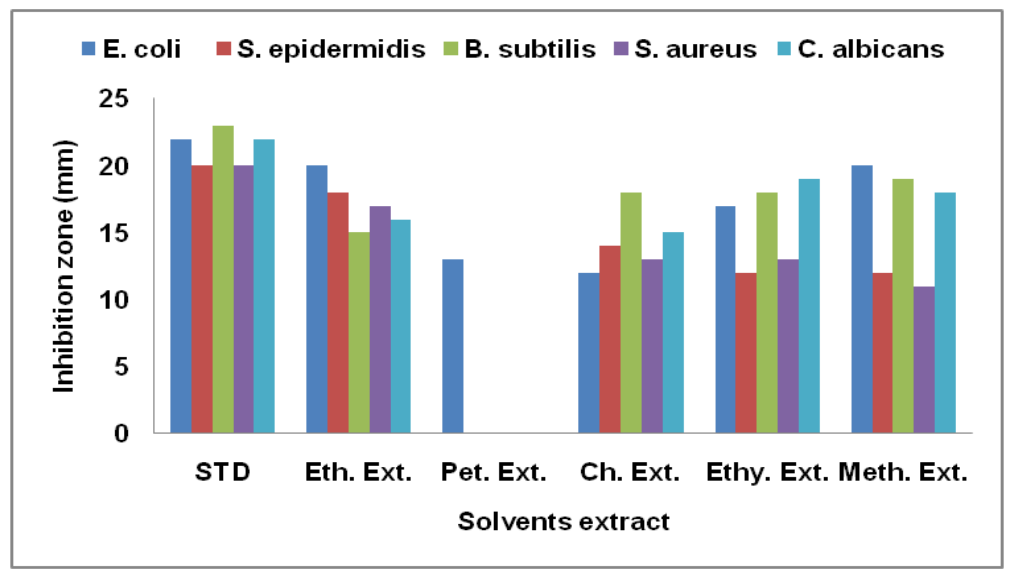

Fig. 1: Antimicrobial activity of $T$. occidentalis seeds extracts against standard tested microorganisms, $S T D=$ standard streptomycin, Eth Ext= total (crude) ethanol extract, Pet Ext= petroleum ether extract (successive), $\mathrm{Ch}$ Ext= chloroform extract (successive), Ethy Ext= ethyl acetate extract (successive), Meth Ext= methanol extract (successive). The values represent the mean of the three determinants 


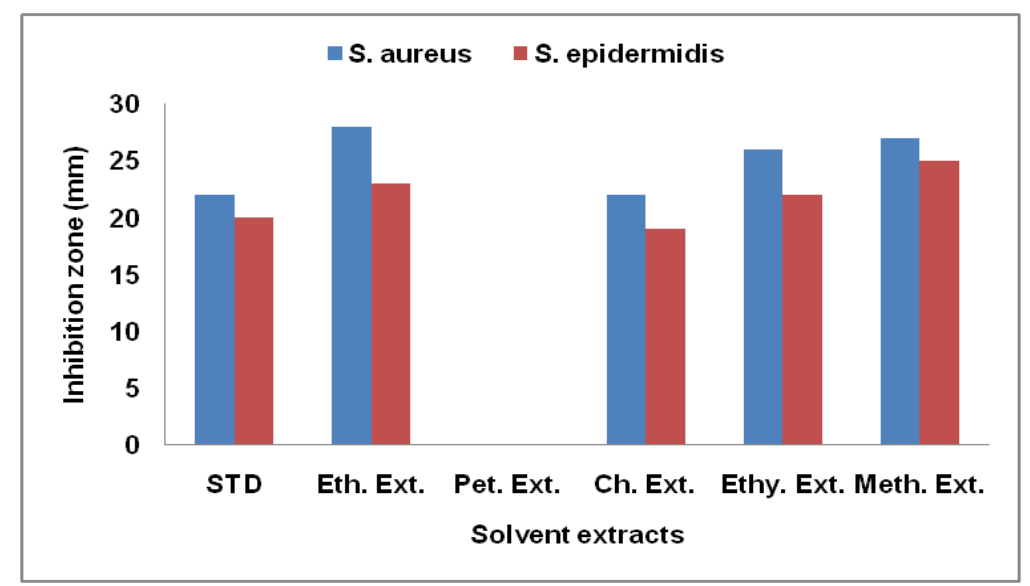

Fig. 2: Antimicrobial activity of T. occidentalis seeds extracts against isolated bacteria, STD= standard Streptomycin, Eth Ext= total (crude) ethanol extract, Pet Ext= petroleum ether extract (successive), Ch Ext= chloroform extract (successive), Ethy Ext= ethyl acetate extract (successive), Meth Ext= methanol extract (successive). The values represent the mean of the three determinants

\section{Antimicrobial activity}

The antimicrobial activity of $T$. occidentalis seeds extracts, against standard microorganisms (fig. 1) was found to be highest against $E$. coli followed by B. subtilis, C. albicana, S. aureus and S. epidermidis. The highest activity was shown by an alcoholic (ethanol, methanol) followed by the ethyl acetate, whereas, the moderate activity showed by the chloroform extract. The petroleum ether had the least activity, only E. coli was found to be sensitive with low inhibition zone.

Regarding the activity against the isolated $S$. aureus and $S$. epidermidis bacteria (fig. 2), the two bacteria were highly sensitive to the ethanol, methanol and ethyl acetate extracts, and their activity was found to be higher than that of standard Streptomycin. The chloroform extract showed moderate antibacterial activity against the isolated bacteria. The two bacteria were resistant or insensitive towards the petroleum ether extract.

\section{DISCUSSION}

The diverse health benefit of the plants is usually known to be through the numerous phytochemicals extractions [1]. The percentage yield of T. occidentalis seeds extracts was found to be different with solvents used in the extraction. The low polar solvents revealed percentage yield less than the solvents with high polarity. These results clearly indicate that $T$. occidentalis contains a great deal more of polar compounds than non-polar compounds. The total ethanol (96\%) extract showed percentage yield of $73.7 \% 9(\mathrm{w} / \mathrm{w})$, being greater than any of the successive extracts. This may be attributed to the fact that, the $96 \%$ ethanol is a universal solvent possess polar and non-polar moieties, and hence when used solely as an extraction solvent was capable of extracting the widest variation of chemical compounds.

The preliminary phytochemical analysis of $T$. occidentalis seeds extracts (table 2) revealed the presence of secondary metabolites which are important for medicinal activity. The screening revealed the presence of tannin in all assessed extracts, it was found to be highly concentrated in alcoholic (ethanol and methanol) extracts. Whereas, in the petroleum ether extract tannin was found in slightly amount, addition to the absence of the all other tested phytochemicals. Alcoholic (ethanol and methanol) extracts revealed the presence of all tested phytochemicals except carbohydrates, sterols and saponins which were found to be absent in all assessed extracts. The ethyl acetate extract revealed the presence of phytochemicals the same as in alcoholic extracts with the slightly difference in the absence of alkaloids. Addition to tannin the chloroform extract showed the presence of flavonoid and alkaloids only. The presence of tannins, flavonoids, alkaloids and terpenoids which are well known for their antimicrobial activity $[1,15]$ suggest that T. occidentalis seeds extracts are endowed with beneficial antimicrobial effect and could serve as a base of future drugs.

The present study represents a broad spectrum antimicrobial activity of $T$. occidentalis seeds extracts, although the degree of susceptibility differs between different organisms. Inhibition of microorganisms by T. occidentalis seeds extracts, against standard microorganisms (fig. 1) was in the order of alcohol, ethyl acetate, chloroform and petroleum ether extracts. Highest was against $E$. coli followed by $B$. subtilis. The MICs of T. occidentalis extracts against standard tested microorganisms; P. aeruginosa, E. coli, B. subtilis, $S$. aureus and C. albicans were found to be $6.25 \mathrm{mg} / \mathrm{ml}, 25 \mathrm{mg} / \mathrm{ml}, 25$ $\mathrm{mg} / \mathrm{ml}, 12.5 \mathrm{mg} / \mathrm{ml}$ respectively for the ethanol, methanol and ethyl acetate extracts. For the chloroform extract was $6.25 \mathrm{mg} / \mathrm{m}$ for $P$. aeruginosa and $12.5 \mathrm{mg} / \mathrm{ml}$ for the other.

Regarding the antimicrobial activity results of $T$. occidentalis seeds extracts against the isolated skin infecting bacteria (fig. 2), both isolated bacteria; $S$. aureus and $S$. epidermidis were highly sensitive towards the extracts excluding the petroleum ether fraction. The activity order was similar to that observed against standard microorganisms with MIC value of $6.25 \mathrm{mg} / \mathrm{ml}$ against $S$. aureus and $S$. epidermidis for ethanol, methanol and ethyl acetate, whereas, chloroform showed MIC values of $25 \mathrm{mg} / \mathrm{ml}$ against the two isolated bacteria. The results of $T$. occidentalis extracts against the two isolated bacteria, which are well known for their causing of skin diseases and infections $[1,10,16,17]$ compatible with antibacterial activity of the plant [18] and confirm the traditional used of the plant for the treatment of skin diseases and infections [4].

Based on the polarity of solvents and the phytochemical screening (table 2), the observed activity displays a wide variation in correlation with the polarity of extract solvents used, and the activity was found to be proportional to the polarity of the solvents, as well as the tannin concentration which was well known for the antimicrobial activity [19-25]. This may be attributed to the fact that the chemical constituents responsible for the antimicrobial activity are of high polarity, the main of such compounds are tannins. Finally, it should be stated that preliminary phytochemical analysis results obtained seem to comply with the antimicrobial activity results.

\section{CONCLUSION}

Phytochemical study of different solvent extracts of-of T. occidentalis seeds revealed the presence of alkaloids, terpenoids, flavonoids and tannins. In the present study, it was clear that ethanol and methanol extracts of $T$. occidentalis seeds contains an abundant amount of tannins which were well known for their antimicrobial effect. Therefore, further research is needed to isolate, purify and characterize the bioactive compounds of the plant. 


\section{ACKNOWLEDGEMENT}

Authors are thankful to Khartoum Dermatological Diseases Hospital/Sudan for providing the skin infected sample.

\section{AUTHORS CONTRIBUTION}

Design of the work, interpretation of data and writing and correction of the manuscript was done by the first author Dr. Ikram Mohamed Eltayeb. The experimental part of the work was done by Mr. Abdeen Salim Hamid.

\section{CONFLICT OF INTERESTS}

Declared none

\section{REFERENCES}

1. Arunkumar K, KR Chandrashekar. Phytochemical evaluation and in vitro antimicrobial and antioxidant studies of leaf and stem bark extracts of Polyalthia fragrans (dalz.) bedd.-an endemic species of Western Ghats. Int J Pharm Pharm Sci 2017;9:20-4.

2. Benahmed-Bouhafsoun A, Djied S, Mouzaz F, Kaid-Harche M. Phytochemical composition and in vitro antioxidant activity of Chamaerops humilis L. extracts. Int J Pharm Pharm Sci 2013;5:741-4.

3. Naser B, Bodinet C, Martin Tegtmeier M, Lindequist U. Thuja occidentalis (Arborvitae): a review of its pharmaceutical, pharmacological and clinical properties. J EvidenceBased Complementary Altern Med 2005;2:69-78.

4. Tardif J, Stevenson D. Radial growth-climate association of Thuja occidentalis $\mathrm{L}$. at the northwestern limit of its distribution, Manitoba, Canada. Dendrochronologia 2001;19:2-10.

5. Biswas R, Mandal SK, Dutta S, Bhattacharyya SS, Boujedaini N, Khuda-Bukhsh AR. The fraction of Thuja occidentalis demonstrates major anti-cancer potentials: evidence from in virto studied on A375 Cells. J Evidence-Based Complementary Altern Med 2011; 1:23-9.

6. Felter H. A treatise on Thuja occidentalis. Drug Treatise, Number I. Cincinnati, Ohio: Lloyd Bros; 1904.

7. Pak J, Bot JN, Ahmad M, Mehjabeen M, Ul-haq Z, Alam SM, et al. Antimicrobial screening of some medicinal plants of Pakistan. Pak J Sci Ind Res 2010;43:1773-5.

8. Offergeld R, Reinecker C, Gunz E. Mitogenic activity of high molecular polysaccharide fractions isolate the Cupressaceae Thuja occidentalis L. enhanced cytokine-production the polysaccharide, g fraction (TPSg). Leuk J 1992;6:189-91.
9. McCaig LF, McDonald LC, Mandal S, Jernigan DB. Staphylococcus aureus-associated skin and soft tissue infections in ambulatory care. Emerging Infectious Diseases J 2012;12:443-58.

10. Adeleye IA, Ogunniyi AA, Omonigbehin EA. Antimicrobial activity of some local herbs on common skin pathogens. Biol Res Com 2003;15:231-6.

11. Otto M. Staphyloccus epidermidis-the accidental pathogen. Nat Rev Microbiol 2010;7:555-67.

12. Sofowora A. Recent trends in research into African medicinal plants. J Ethnopharmacol 1993;38:197-208.

13. Evans, William Charles. Trease and Evans' Pharmacognosy. Elsevier Health Sciences; 2009.

14. Kavanagh FS. Analytical microbiology. 2nd edition. Academic Press: New York and London; 1972. p. 11.

15. Cowan M. Plant products as antimicrobial agents. Clin Microbiol Rev 1999;12:564-82.

16. Jawetz E, Janet S, Nicholas L, Edwards E. Skin microorganism. Medical Microbiology, Lange International NY; 1978. p. 25-7.

17. Mann A, Yahaya Y, Banso A, Ajayi GO. Phytochemical and antibacterial screening of Anogeissus leiocarpus against some microorganisms associated with infectious wounds. Afr J Microbiol Res 2008;2:60-2.

18. Jasuja N, Sharma S, Saxena R, Choudhary J, Sharma R, Joshi S Antibacterial, antioxidant and phytochemical investigation of Thuja occidentalis leaves. J Med Plant Res 2013;7:1886-93.

19. Ho KY, Tsai CC, Huang JS, CP Lin TC, Lin CC. Antimicrobial activity of tannin components from Vaccinium vitis-idaea L. J Pharm Pharmacol 2001;53:187-91.

20. Meigy NM, Meta M, Natsir D. Test of antimicrobial activity of tannins extract from guava leaves to pathogens microbial. Int Asian Res J 2014;2:43-50.

21. Ngoupayo J, Assonfack FRM, Chelea M, Djiele NP, Ndelo J. Evaluation of the antimicrobial activity of tannin extracted from the barks of Erythrophleum guineensis (Caesalpiniaceae). J Pharmacol Phytoch 2016;5:287-91.

22. Lim SH, Darah, Jain K. Antimicrobial activities of tannins extracted from Rhizophora apiculata barks. J Trop Forest Sci 2006;18:59-65.

23. Doss A, Mohammed MH, Dhanabalan R. Antibacterial activity of tannins from the leaves of Solanum trilobatum L. Ind J Sci-Tech 2009:2:41-3.

24. Scalbret A. Antimicrobial properties of tannins. Phytochemistry 1991;30:3875-83

25. Giovana MLF, Ana LFV, Bianca WB, Silvana G, Saulo FA, Suzelei de $\mathrm{CF}$, et al. Antimicrobial activity and rates of tannins in Stryphnodendron adstringens Mart. Accessions collected in the Brazilian Cerrado. Am J Pant Sci 2013;4:2193-8. 